\title{
Nondysraphic intramedullary spinal cord lipomas: a review
}

\author{
Harjinder Singh Bhatoe, M.Ch., Prakash Singh, M.Ch., Aarti Chaturvedi, M.D., \\ Kavita Sahai, M.D., Vibha DutTa, M.D., and P. K. Sahoo, M.CH. \\ Departments of Neurosurgery, Imaging, and Pathology, Army Hospital (Research \& Referral), \\ Delhi Cantt, India
}

\begin{abstract}
Object. Lipomas of the spinal cord are often a component of spinal dysraphic states. Nondysraphic intramedullary spinal cord lipomas are rare, and their presentation, in the form of gradually worsening myelopathy, is nonspecific. The authors report on the methods used for diagnosis and treatment in patients presenting with these lesions at their institution, and they review the relevant literature.

Methods. The authors treated 14 patients who presented with intramedullary lipomas over a period of 12 years. None of these patients had segmentation anomaly or dysraphism of the spine, or any hindbrain anomaly. Admission magnetic resonance images were diagnostic in all patients. All tumors were located dorsally in the spinal cord, the majority of them in the cervicodorsal cord. The lipomas were partially excised with the help of a carbon dioxide laser in all patients in an attempt to preserve neurological function. All patients attained improvement in their sensory and motor symptoms.

Conclusions. Because these lesions do not have a clear-cut margin, it is vital to preserve neurological function at the time of surgery, even if it entails incomplete resection.
\end{abstract}

\section{KEY WORDS • lipoma • spinal cord tumor • extent of resection}

Intramedullary spinal cord lipomas are rare lesions, constituting less than $1 \%$ of all intramedullary spinal tumors. Most of the time, lipomas in the spinal cord occur in association with the syndrome of spinal dysraphism, and these lesions communicate with subcutaneous lipomas through a defect in the posterior elements of the spine. Nondysraphic intramedullary spinal cord lipomas are very rare, and there are only a few reports comprising small series in the literature; Lee, et al., ${ }^{7}$ in a review published in 1995, stated that there were nearly 100 documented cases of spinal cord lipomas worldwide.

\section{CLINICAL MATERIAL AND METHODS}

\section{Clinical Profile}

A retrospective analysis was conducted on the records of 14 patients with intramedullary lipomas of the spinal cord who were treated in four different service hospitals over a period of 12 years (1991-2003). Information on the patients' clinical profile, level of spinal cord involvement, and surgical management of the lesions is given in Table 1. There were 10 male and four female patients; the mean age at presentation was 31.5 years (range 6-42 years). All patients presented with gradually worsening quadri- or paraparesis. Dysesthesia over the trunk and the limbs was a universal complaint. Only one patient who had lumbar spinal cord involvement experienced urinary incontinence; bladder function was preserved in the rest. Sensory

Abbreviation used in this paper: $\mathrm{MR}=$ magnetic resonance. involvement was inconsistent, with six patients showing varying degrees of suspended exteroceptive sensation impairment. Six patients had sensory ataxia, with a feeling of cotton wool over the feet and slippage of footwear, accompanied by impairment of joint and position sense. None of these patients had external visible stigmata of a dysraphic spine.

\section{Neuroimaging Evaluations}

All patients were evaluated using MR imaging, which was performed on a $0.5 / 1$-tesla machine with a conventional spin-echo protocol in the sagittal, coronal, and axial planes. The images were obtained in $\mathrm{T}_{1}$ - and $\mathrm{T}_{2}$-weighted sequences and in $\mathrm{T}_{1}$-weighted fat-suppression sequences. Plain radiography of the involved spinal region was performed to exclude any segmentation or fusion anomaly. Findings on MR images were the classic appearance of lipoma; a uniformly hyperintense lesion on $\mathrm{T}_{1}$-weighted and a hypointense lesion on $\mathrm{T}_{2}$-weighted images, and demonstrating fat suppression. All lipomas were located dorsally and spanned three or four vertebral levels (Figs. 1-4). The involved spinal cord was expanded and pushed anteriorly. The anatomical level at which the lipoma was located is given in Table 1. The cervicodorsal spinal cord was the most common region of involvement, followed by the cervical, dorsal, lumbar, and cervicomedullary cord, in that order. Although the lumbar spinal cord ended at L-2 in one patient with a lumbar lipoma, there was no other feature of dysraphic anomaly. There was no evidence of syrinx formation or hindbrain anomaly. 
TABLE 1

Clinical profile, spinal involvement, and treatment in 14 patients with intramedullary lipomas*

\begin{tabular}{|c|c|c|c|c|}
\hline $\begin{array}{l}\text { Case } \\
\text { No. }\end{array}$ & $\begin{array}{l}\text { Age (yrs) } \\
\text { Sex }\end{array}$ & $\begin{array}{l}\text { Motor } \\
\text { Strength }\end{array}$ & $\begin{array}{l}\text { Anatomical } \\
\text { Level }\end{array}$ & $\begin{array}{l}\text { Postop } \\
\text { Outcome }\end{array}$ \\
\hline 1 & $43, \mathrm{M}$ & $3 / 5$ & C4-6 & $\begin{array}{l}\text { motor strength } 4 / 5 \text {, relief of } \\
\text { dysesthesia }\end{array}$ \\
\hline 2 & $32, \mathrm{M}$ & $3 / 5$ & $\mathrm{~T} 2-6$ & motor strength $3 / 5$ \\
\hline 3 & $37, \mathrm{M}$ & $3 / 5$ & C6-T3 & motor strength $3 / 5$ \\
\hline 4 & $40, \mathrm{M}$ & $4 / 5$ & C6-T2 & $\begin{array}{l}\text { motor strength } 4 / 5 \text {, relief of } \\
\text { dysesthesia }\end{array}$ \\
\hline 5 & $12, \mathrm{~F}$ & $4 / 5$ & L1-2 & no change, relief of dysesthesia \\
\hline 6 & $42, \mathrm{M}$ & $4 / 5$ & L-2 & no change, relief of dysesthesia \\
\hline 7 & $24, \mathrm{M}$ & $3 / 5$ & C7-T4 & $\begin{array}{l}\text { motor strength } 4 / 5 \text {, relief of } \\
\text { dysesthesia }\end{array}$ \\
\hline 8 & $31, \mathrm{M}$ & $4 / 5$ & C6-T1 & no change, relief of dysesthesia \\
\hline 9 & $23, \mathrm{~F}$ & $3 / 5$ & $\begin{array}{l}\text { C6-T6 } \\
\text { (dumbbell) }\end{array}$ & $\begin{array}{l}\text { motor strength } 5 / 5 \text {, relief of } \\
\text { dysesthesia }\end{array}$ \\
\hline 10 & $30, \mathrm{M}$ & $4 / 5$ & $\mathrm{FM}-\mathrm{C} 2$ & no change, relief of dysesthesia \\
\hline 11 & $28, \mathrm{~F}$ & $4 / 5$ & $\mathrm{~T} 1-4$ & no change, relief of dysesthesia \\
\hline 12 & $30, \mathrm{~F}$ & $4 / 5$ & $\mathrm{C} 7-\mathrm{T} 4$ & no change, relief of dysesthesia \\
\hline 13 & $6, \mathrm{M}$ & $3 / 5$ & FM-C4 & no change \\
\hline 14 & $27, \mathrm{M}$ & $4 / 5$ & C6-T4 & no change, relief of dysesthesia \\
\hline
\end{tabular}

$* \mathrm{FM}=$ foramen magnum.

\section{Surgical Methods}

Surgery was performed independently by three practitioners. All 14 patients underwent surgery after being placed prone. The involved portion of the spinal cord was exposed by laminectomy, and the dura mater was opened to expose the cranial and caudal extent of the lipoma. The lesion was partly visible subpially in seven patients, and was completely intramedullary in the rest. Debulking was accomplished using microsurgical techniques with a car-

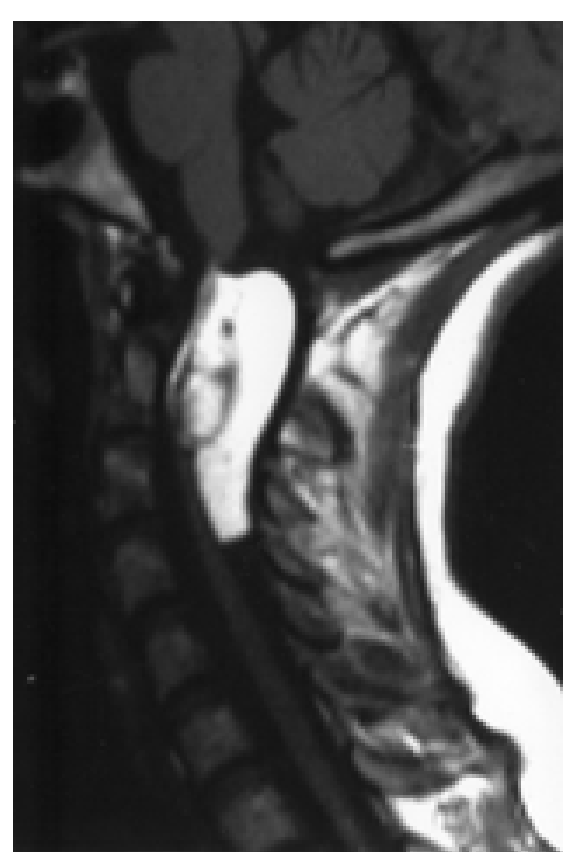

Fig. 1. Sagittal $\mathrm{T}_{1}$-weighted MR image of the craniocervical region demonstrating an intramedullary lipoma.
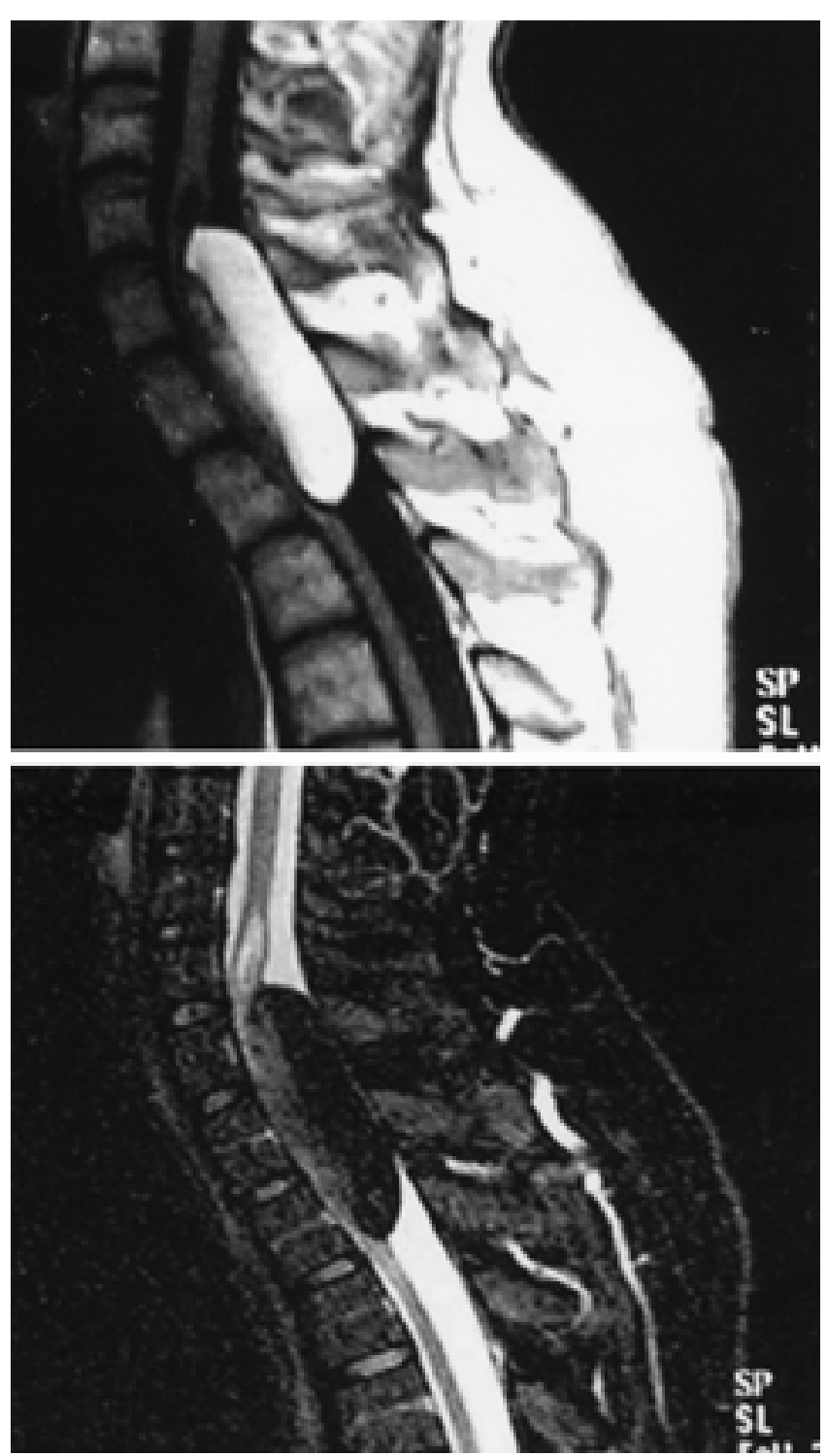

Fig. 2. Upper: Sagittal $\mathrm{T}_{1}$-weighted MR image of the cervicodorsal spinal cord demonstrating an intramedullary lipoma. Lower: Fat-suppression MR image of the same lesion.

bon dioxide laser set at an energy level of 6 to $15 \mathrm{~W}$. No definite plane of cleavage could be found in any of the patients. Debulking reached the extent of 60 to $80 \%$ according to the perioperative assessment made by the operating surgeon. Physical traction or laser application on the portion of the lipoma adherent to the spinal cord was scrupulously avoided. No attempt was made to define the lipoma-cord interface. Intraoperative ultrasonography was not used, and the dura mater was closed after hemostasis.

\section{RESULTS}

The immediate postoperative recovery was uneventful in all patients. There were no wound-related problems. Neurological improvement was universally observed in the following forms: 1) relief of dysesthesia and pain in 11 


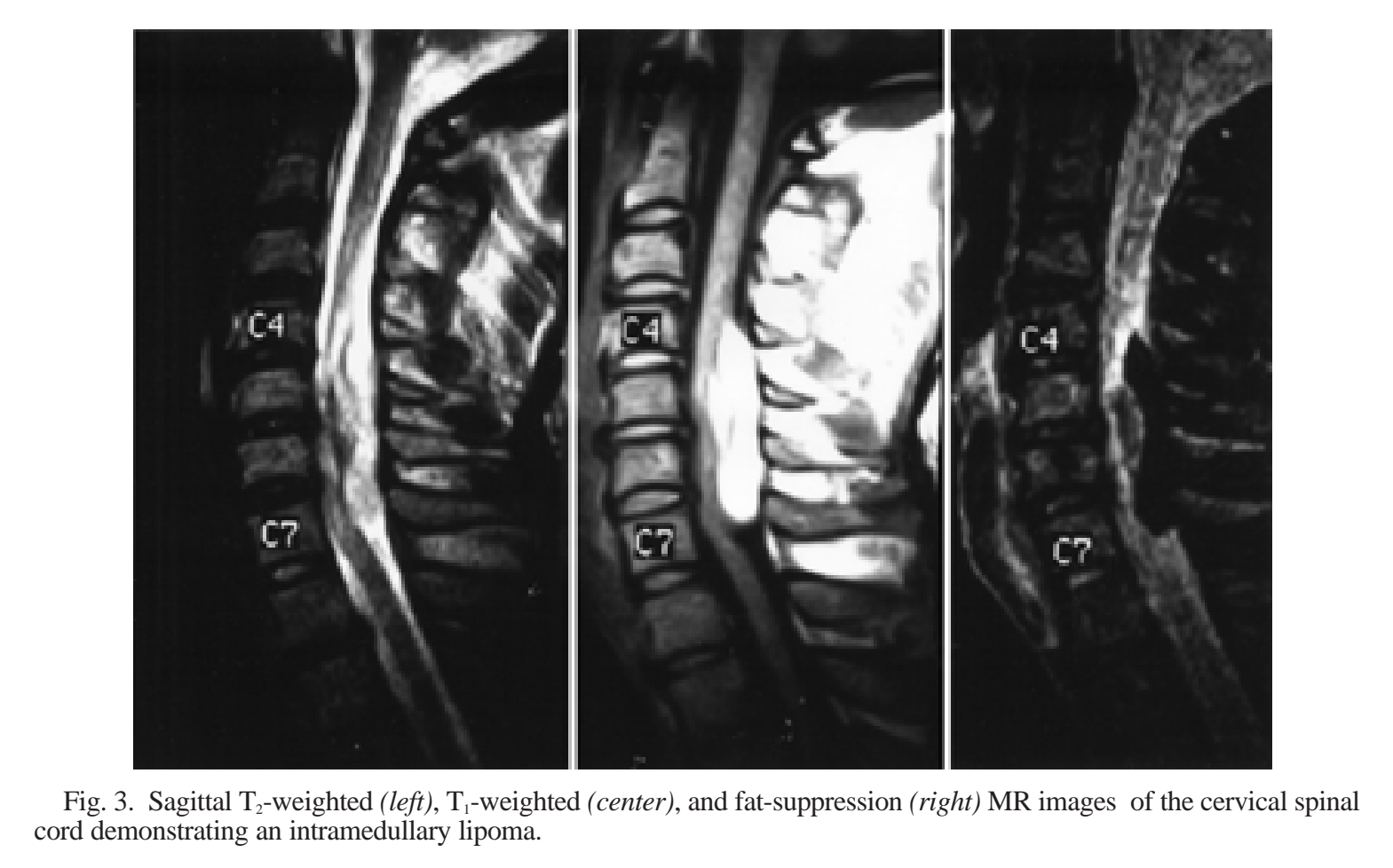

of 14 patients; 2) improvement in motor power in four of 14 patients; and 3 ) improvement in sensory ataxia in seven of 14 patients.

\section{Histopathological Findings}

All tumor samples were received as multiple bits of pale, fatty tissue. These were fixed overnight in $10 \%$ formalin, and subsequently stained with $\mathrm{H}$ and $\mathrm{E}$. On microscopic inspection, the sections showed sheets of adipose tissue. No angiomatous or neuroglial elements were visualized in any of the tumors. The diagnosis of lipoma was confirmed in all patients. Postoperative MR imaging was performed after 4 weeks (at the first follow-up review), and demonstrated reduction in the size of the lesion. All patients were followed up for a period ranging from 1 to 7 years (mean 2 years and 3 months), during which they have remained neurologically stable. None of the patients worsened or was required to undergo repeated surgery.

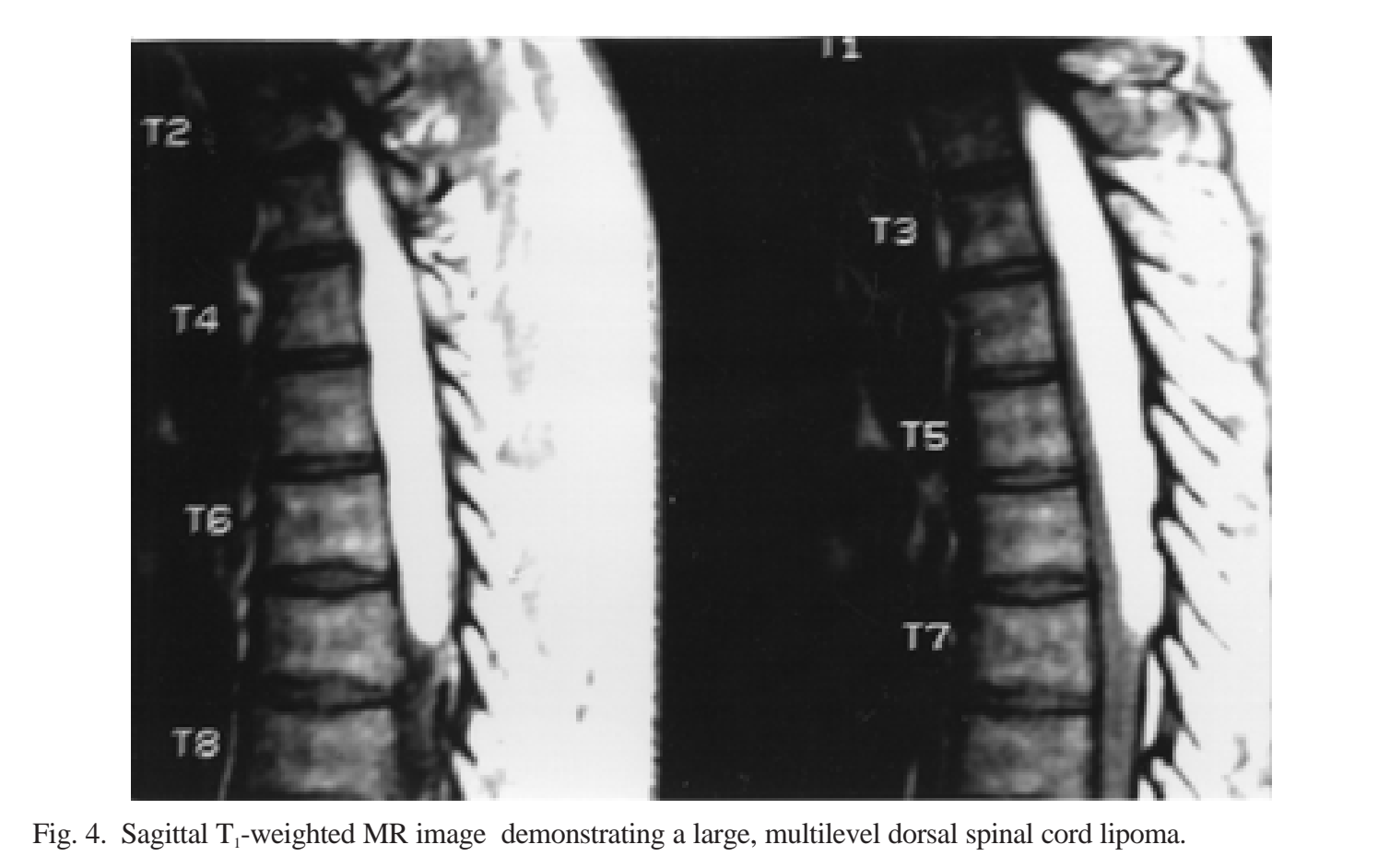




\section{DISCUSSION}

Spinal lipomas are usually associated with dysraphism, in which the intraspinal component communicates with a subcutaneous lipoma through a defect in the posterior elements of the spine. Nondysraphic intramedullary spinal cord lipomas are very rare, ${ }^{2,4,13}$ with only approximately 100 well-documented cases reported worldwide. ${ }^{7}$

\section{Origin of the Lesions}

Intramedullary lipomas of the spinal cord are the most common dysembryogenic lesions and account for nearly $1 \%$ of all intramedullary tumors that have an embryological basis. ${ }^{15}$ That these lesions have an embryological basis is evident from tumors detected during infancy. ${ }^{10}$ During the 3rd week of embryonic development, the edges of the developing neural plate elevate and form folds. As the neural folds approach each other in the midline, the superficial ectoderm trails their leading edge. Cellular processes from opposite sides of neural cells make contact, recognition occurs, and cell adhesions close the tube. At this point the superficial ectoderm closes and separates by dysjunction from the neural tube. Mesenchyme streams into the space between the neural tube and the superficial ectoderm. This mesenchyme will generate vasculature of the spinal cord, and develops into the meninges and vertebral column. ${ }^{6}$ It is postulated that lipomas develop when there is premature dysjunction of the cutaneous ectoderm from the forming neural tube. The surrounding mesenchyme migrates into the developing neural tube below the cutaneous ectoderm. In this milieu, the mesenchyme, instead of differentiating into dura mater, changes into fat.

The presence of intact meninges and posterior elements of the spine over the intramedullary lipoma, however, indicates that there is another process for differentiation, in which there is complete closure of the neural tube with some mechanism of mesenchymal migration into the developing neural tube prior to closure. The developing posterior elements are displaced laterally, and roots are seen at the lipoma-spinal cord interface. ${ }^{8}$ Almost always, these lipomas are located over the posterior aspect of the cord, most frequently over the cervicodorsal region. There have been instances of involvement of the cervicobulbar region, multiple noncontiguous lesions, ${ }^{16}$ or even involvement of the entire spinal cord. ${ }^{14}$ There has been one report of multiplicity of intradural subpial lipomas without spinal dysraphism; this points to a dysembryogenic basis similar to that seen in patients with spinal dysraphism that results in lipomas, but in which the defect is not severe enough to give rise to coexisting vertebral and soft-tissue anomalies. ${ }^{16}$

\section{Patterns of Presentation}

Two distinct patterns of presentation have been noticed in intramedullary lipomas. One group presents during infancy and childhood, often as tetraplegia or floppy baby syndrome; the neurological manifestations are thought to be due to birth trauma to the spinal cord. ${ }^{10,12}$ In the child with quadriplegia described by Mori, et al. ${ }^{10}$ these authors diagnosed floppy infant syndrome; when the child experienced seizures at the age of 7 years, MR imaging revealed a cervicomedullary lipoma with intracranial extension.
Slow-growing intradural lipomas can simulate scapulohumeral muscular dystrophy ${ }^{1}$ or scoliosis. ${ }^{5}$

Manifestations in the other group are often delayed until the third or fourth decade of life. Presentation is extremely subtle, with slowly progressive myelopathy that can remain static for years. These lesions enlarge and produce symptoms due to increased fat deposition in metabolically normal fat cells and are often located in the subpial area. ${ }^{15}$ Patients always present with spinal axis pain and dysesthetic sensory changes. Most of the patients included in the various studies had remained ambulatory and continent, although reports in the literature indicate early neurological deterioration. ${ }^{15}$ The clinical course is by and large indolent, although acute neurological deterioration has been reported; such an event probably indicates exhaustion of the physiological reserve of neurological function as the spinal cord is compressed over the years by the supposedly congenital lesions.

\section{Diagnostic Imaging}

The most sensitive modality for diagnosing intramedullary lipomas preoperatively is MR imaging. Hyperintense lesions seen on $\mathrm{T}_{1}$-weighted images are quite characteristic of lipoma, which can be confirmed by fat-suppression sequences. The lesions are located dorsally, and the cervicothoracic spinal cord is the most common region of involvement. A dumbbell extradural extension through the intervertebral foramen is extremely rare. ${ }^{11,16}$

\section{Surgical Options}

Surgery for intramedullary lipomas requires a firm commitment about the extent of surgical removal planned because the safety margin for neurological preservation is extremely thin. The dangers associated with attempted total removal have been recognized for decades, ever since these tumors have been described. ${ }^{3}$ Because of the indolent course in most patients, decompression has been advocated by most neurosurgeons. Intraoperative ultrasonography can be performed to define the cranial and caudal extent of the lesion, because these lipomas are anechoic. Myelotomy is performed either in the midline or over the thinnest overlying neural tissue. Pial sutures are inserted for retraction and the lipoma is debulked using a carbon dioxide laser. Because of the high water content of these lesions, the laser vaporizes the fatty tissue without physical manipulation of the neural tissue. ${ }^{9}$

The natural history of surgically treated lesions is usually uneventful, with neurological deficits remaining stable. The pain disappears due to relief of pressure on the dorsal columns. No recurrences of these lesions have been reported.

\section{CONCLUSIONS}

Nondysraphic intramedullary lipomas of the spinal cord are rare lesions with a congenital origin. Their course is indolent, with slowly progressing myelopathy, although rapid neurological deterioration can also develop. In childhood, the presentation may be in the form of floppy infant syndrome, scoliosis, or a limb-girdle pattern of muscle wasting. Magnetic resonance imaging is diagnostic and surgical decompression is mandatory to obviate 


\section{Nondysraphic intramedullary spinal cord lipomas: a review}

sudden, irreversible neurological damage. The long-term results of surgical decompression are satisfactory.

\section{References}

1. Drapkin AJ: High cervical intradural lipoma. J Neurosurg 41: 699-704, 1974

2. Dyck P: Intramedullary lipoma. Diagnosis and treatment. Spine 17:979-981, 1992

3. Elsberg CA: Tumors of the Spinal Cord and the Symptoms of Irritation and Compression of the Spinal Cord and Nerve Roots: Pathology, Symptomatology, Diagnosis and Treatment. New York: Hoeber, 1925

4. Giuffre R: Intradural spinal lipomas. Review of the literature (99 cases) and report of an additional case. Acta Neurochir 14: 69-95, 1966

5. Kim CH, Wang KC, Kim SK, et al: Spinal intramedullary lipoma: report of three cases. Spinal Cord 41:310-315, 2003

6. Langman J: Medical Embryology: Human DevelopmentNormal and Abnormal. Baltimore: Williams \& Wilkins, 1963

7. Lee M, Rezai AR, Abbott R, et al: Intramedullary spinal cord lipomas. J Neurosurg 82:394-400, 1995

8. McLone DG, Mutluer S, Naidich TP: Lipomeningoceles of the conus medullaris, in Raimondi AJ (ed): Concepts in Pediatric Neurosurgery. Basel: Karger, 1982, Vol 3, pp 171-177

9. McLone DG, Naidich TP: Laser resection of fifty spinal lipomas. Neurosurgery 18:611-615, 1986

10. Mori K, Kamimura Y, Uchida Y, et al: Large intramedullary lipoma of the cervical cord and posterior fossa. Case report. J Neurosurg 64:974-976, 1986

11. Mrabet A, Zouari R, Mouelhi T, et al: [Cervicobulbar intramedullary lipoma. Apropos of a case with review of the literature.] Neurochirurgie 38:309-314, 1993 (Fre)

12. Naim-Ur-Rahman, Salih MA, Jamjoom AH, et al: Congenital intramedullary lipoma of the dorsocervical spinal cord with intracranial extension: case report. Neurosurgery 34: 1081-1084, 1994

13. Pani KC, Chopra JS, Kak VK: Intramedullary lipoma of the spinal cord. Neurochirurgia 15:33-35, 1972

14. Razack N, Jimenez OF, Aldana P, et al: Intramedullary holocord lipoma in an athlete: case report. Neurosurgery 42: 394-396, 1998

15. Schwartz TH, McCormick PC: Intramedullary tumors of the spinal cord, in Batjer HH, Loftus CM (eds): Textbook of Neurological Surgery: Principles and Practice. Philadelphia: Lippincott Williams \& Wilkins, 2003, Vol 2, pp 1864-1871

16. Subramaniam P, Behari S, Singh S, et al: Multiple subpial lipomas with dumb-bell extradural extension through the intervertebral foramen without spinal dysraphism. Surg Neurol 58: $338-343,2002$

Manuscript received November 22, 2004.

Accepted in final form January 5, 2005.

Address reprint requests to: Lieutenant Colonel Harjinder Singh Bhatoe, M.Ch., Department of Neurosurgery, Army Hospital (Research \& Referral), Delhi Cantt 110010, India. email: hsbhatoe@ indiatimes.com. 